\title{
Local villagers' perceptions of wolves in Jiuzhaigou County, western China
}

Yu Xu, Biao Yang, Liang Dou

While there have been increasing numbers of reports of human-wolf conflict in China during recent years, little is known about the nature of this conflict. In this study, we used questionnaires and semi-structured interviews to investigate local villagers' perceptions of wolves in Jiuzhaigou County, western China. We sampled nine villages with more frequent reports of wolf depredation to the local government, but included three villages near alpine pastures in which reports of depredation were less frequent. We sampled 100 residents, a subset of the local population who were more likely to have had experience with wolves. During the preceding three years, most families of the respondents grazed livestock on alpine pastures, and most of them reported that their livestock suffered from depredation by wolves. The mean value of the reported annual livestock loss rates was considerably higher in villages that reported depredation more frequently than in those with less frequent reports of depredation. Most respondents in the more frequently depredated villages perceived an increase in wolf populations, whereas many in the less frequently depredated villages perceived a decrease in wolf populations in their areas. People's attitudes towards wolves did not differ significantly between these two village categories. The majority of the respondents were negative in their attitude to wolves, despite a prevalent Tibetan culture that favors the protection of wildlife. People's negative attitude was directly related to the number of livestock owned by their family. Those with a larger number of livestock were more likely to have a negative attitude towards wolves. Factors such as village category, ethnicity, age and education level did not influence people's attitudes to wolves. We suggest that improved guarding of livestock and provision of monetary support on human resources and infrastructure may mitigate human-wolf conflicts in this region. 
4

$5 \mathrm{Yu} \mathrm{Xu}^{1 *}$, Biao Yang ${ }^{2 *}$, Liang Dou $^{2}$

6

$7{ }^{1}$ School of Resources and Environmental Sciences, Pingdingshan University, Pingdingshan 467000,

8 China

$9 \quad{ }^{2}$ Key Laboratory of Bio-Resources and Eco-Environment of Ministry Education, School of Life

10 Sciences, Sichuan University, Chengdu 610064, China

$11 *$ These two authors contributed equally to this work

12 Corresponding author: Yu Xu, Email: xuyu608@163.com

13 
Introduction

15 Conflicts between wolves and humans are common worldwide, because of human fear of wolves and

16 in particular, financial loss due specifically to injury to and loss of livestock that wolves cause (Mech

17 \& Boitani 2003; Treves \& Karanth 2003; Bisi et al. 2007). As wolf populations expand or humans

18 encroach on their habitats, economic losses to wolves increase and conflicts have become increasingly

19 likely, presenting unique challenges for the conservation and management of wolves (Mech \& Boitani

20 2003; Naughton-Treves, Grossberg \& Treves 2003; Bisi et al. 2007; Lescureux \& Linnell 2013).

21 To conserve wolves, many researchers have conducted studies aimed at understanding the

22 conflicts. Managers need to know the perceptions and attitude of local people to wolves and their

23 conservation programs. In particular, by determining which people are more negative towards wolves,

24 managers are potentially able to find solutions to improving people's tolerance towards wolves (Treves

25 \& Karanth 2003; Suryawanshi et al. 2013). It has been pointed out that people's attitude depends

26 mainly on their residence, age, gender, education and income level, and former experience with wolves

27 (for a review of 38 surveys see Williams, Ericsson \& Heberlein 2002; Ericsson \& Heberlein 2003;

28 Naughton-Treves, Grossberg \& Treves 2003; Røskaft et al. 2007; Skogen \& Thrane 2007). Yet, it is

29 hard to find a widely accepted management policy, because of regional variation and different factors

30 affecting attitudes (Bjerke, Reitan \& Kellert 1998; Bisi et al. 2007). Given this, one has to learn more

31 about the characteristics of human-wolf conflicts and human attitudes towards wolves, especially for

32 regions where conflicts have been reported frequently but available knowledge is very scarce.

China has a large wolf population which is mainly distributed in areas with relatively few

34 anthropogenic changes, in the Qinghai-Tibet Plateau, the Mongolia Plateau and the Northeast Plain. In

35 1998, the number of wolves in China was estimated as about 6,000 individuals (Wang 1998, Yang

36 2008). In this year, wolves were listed as a vulnerable species in the China Red List (Wang 1998), and

37 since then, all hunting has been banned for this legally protected animal. In 2003, China was estimated 
38 to have a population of as many as 12,500 individuals (Mech \& Boitani 2003). We are not aware of

39 any more recent estimates, although the number is likely to have increased substantially in recent years.

40 In recent years in China, there have been increasing reports of injury and loss wolves caused especially

41 to livestock, resulting in increase in human-wolf conflicts (Yang 2008; Zhang et al. 2010; CNC 2012;

42 Li et al. 2013; ScienceNet 2013). Yet, the published literature on this topic is scarce. There have not

43 been any national policies relating to wolves other than some with indirect implications such as

44 auctions of licenses for hunting wild animals (BBC News, 2006) and eco-compensation to mitigate

45 human-wildlife conflicts (Xinhuanet 2014; Yunnan.cn 2014).

46 In this study, we examined local villagers' perceptions of wolves in Jiuzhaigou County, where

47 wolf depredation on livestock has been reported increasingly and the local government is considering

48 management plans for wolves. We aimed to determine wolf population trends, since there have been no

49 data available on the wolf populations in this area. Furthermore, we aimed to determine the level of

50 livestock depredation caused by wolves, and then how people's attitude toward wolves was related to

51 socioeconomic variables, specifically religious belief (e.g., Liu et al. 2011) and livestock ownership

52 (e.g., Tuğ 2005), which are poorly understood.

53

54 Methods

55 Ethics statement

56 The study conformed to the Declaration of Helsinki, and the Ethics Committee of Pingdingshan

57 University approved the research protocol (Ref: 2012003). Verbal informed consent was obtained from

58 all the subjects prior to participation.

59 Study area

60 We conducted the study in Jiuzhaigou County (N 32 $53^{\prime}-33^{\circ} 43^{\prime}$, E $103^{\circ} 27^{\prime}-104^{\circ} 26^{\prime}$; Fig. 1), Aba

61 Tibetan and Qiang Autonomous Prefecture of northwestern Sichuan Province, western China. The 
62 county lies at the northeastern edge of Qinghai-Tibet Plateau and is famous for its Jiuzhai Valley

63 National Park and the traditional cultures of its inhabitants. The area is $5,290 \mathrm{~km}^{2}$, with an elevation

64 ranging from $1,000 \mathrm{~m}$ to $4,500 \mathrm{~m}$. The climate is subtropical to temperate monsoon with a mean annual

65 temperature of $12.7^{\circ} \mathrm{C}$. Total annual rainfall is $550 \mathrm{~mm}$, with $80 \%$ of rainfall occurring between May

66 and October. The county comprises 17 townships and 120 villages, inhabited by Tibetan, Qiang, Hui,

67 Han and other ethnic groups. In 2011, the county's population was 66,246 , with a minority population

68 (ethnic groups other than Han) of 25,090.

Jiuzhaigou County has $3,570 \mathrm{~km}^{2}$ of forested lands (covering about $67 \%$ of the total area), and

70 is the second largest forest area in Sichuan Province. It is rich in alpine grasslands, especially in the

71 northern part, with an area of about $1,200 \mathrm{~km}^{2}$ (Chen 2011). Livestock grazing occurs mainly in the

72 northern region. Yaks are the most common livestock species grazed, but there are a few sheep and

73 goats. Livestock are herded to alpine pastures except during extreme winter weather when they are

74 herded in the cropland around the villages or are stall-fed inside the villages. Livestock of each village

75 graze in exclusive pastures. Families take turns at herding the entire village's stock. Commonly, a

76 couple of people herd the livestock, with the use of one or two shepherd dogs occasionally. The

77 livestock are usually left to range freely on the daytime. At night, the herders bring them back to

78 protective corrals, which are poorly built with low walls and no roof.

Wolves are one of the most important animal species in the local ecosystems. Their large

80 natural prey species are ungulate animals including Elaphodus cephalophus, Capreolus capreolus,

81 Capricornis sumatraensis, Naemorhedus goral, and Pseudois nayaur; smaller prey include Marmota

82 himalayana, Lepus oiostolus, and Ochotona thibetana, and some Galliformes such as Tetraogallus

83 tibetanus, Tetraophasis obscurus, Perdix hodgsoniae, Ithaginis cruentus, Pucrasia macrolopha, and

84 Chrysolophus pictus. However, prey abundance is low (SPAFS 2004; SCUSLS 2011). In the area,

85 livestock depredation by wolves has been reported frequently in recent years, whereas there are few 
86 reports on wolf attacks on humans. The local people reported that wolves usually traveled in groups,

87 and attacked livestock during both the day and night.

88 Fieldwork

89 We carried out the fieldwork in April and May 2012. Following advice from the local forestry bureau,

90 we conducted an interview survey in the northern region where many villages reported frequently

91 livestock depredation by wolves to the local government. We sampled nine villages with frequent

92 reports of depredation. For comparison, we also sampled three villages near alpine pastures in which

93 reports of depredation were less frequent (Fig. 1). The people we interviewed were those who were 16

94 years or older and who grazed their livestock, collected herbs or mushrooms, or carried out other

95 activities in forests and pastures, as they had a better knowledge of the population and activities of

96 wolves (Gros 1998). To foster a comfortable, non-intimidating information exchange process with

97 local residents, the interviews did not include any government staff, and we explained to local residents

98 that the interview was for scientific research purposes only (Kvale 1996).

During interviews, we used a semi-structured questionnaire to minimize the influence of the

100 questions on the response (Wengraf 2001). Interviews were performed orally with responses recorded

101 immediately post-interview into the standardized questionnaire. First, we recorded respondents'

102 personal characteristics, including ethnicity (a variable correlated with the religious belief system), 103 gender, age and education level (three levels: "illiterate", "elementary school", and "secondary and

104 above"). We did not ask their household incomes, because a pilot survey found it difficult to get the

105 true value from respondents. Second, we asked for information about livestock in the past three years,

106 including the annual number of livestock grazed by each family and the annual number of livestock

107 depredated by wolves. Third, we asked their opinions about wolf population trends in their areas over

108 the past 10 years ("increasing", "stable", and "decreasing"). Finally, we assessed their attitudes towards

109 wolves. We included three questions as proxy measures for attitude: (1) "What do you think of 
110 wolves?"; (2) "What do you intend to do in response to livestock depredation by wolves?"; (3) "Do

111 you think that wolves should be protected? If a person thought wolves were bad and detrimental,

112 wanted to kill wolves who were attacking their livestock, and did not wish to protect wolves, we

113 considered that the person was negative towards wolves; if the opposite were the case, we considered

114 the person to have a positive attitude towards wolves. If a person had no strong opinion to the questions,

115 we considered the person to have a neutral attitude towards wolves. If the respondent showed a positive

116 attitude in response to some questions and a negative attitude in response to others, we defined this as a

117 mixed response.

118 Data analysis

119 We first calculated descriptive statistics of responses to analyze the basic information from the

120 interviews. We used to T-tests and Chi-squared tests of independence (Fisher's exact tests were

121 employed if any expected frequency was below 1 or more than $20 \%$ of expected frequencies were less

122 than 5) to compare differences of responses between two village categories, those with more frequent

123 reports of wolf depredation and those less frequent reports of wolf depredation.

Then, we examined how people's attitudes towards wolves were affected by variables of

125 personal characteristics (including ethnicity, age, and education level; gender was not included in the

126 analysis because of only a few respondents were women), and by variables relating to livestock (i.e.

127 annual number of livestock grazed and annual percentage of livestock depredated by wolves). We

128 included all villages but used village category as an additional prediction factor. We excluded one

129 sample with mixed opinion about our measures and pooled positive and neutral attitudes due to the

130 small number of responses in these categories. We also excluded two samples with missing values. We

131 conducted a binary logistic regression, where a totally negative attitude was scored as 1 while a

132 positive or neutral attitude was scored as 0 . In the regression, annual percentage of livestock

133 depredated was considered 0 if there was no livestock grazed (note that this applied only to the 
134 regression and not to the previous descriptive statistics). Categorical variables including village

135 category, ethnicity and education level were converted into a set of dichotomous, dummy-coded

136 variables. We set "villages with more frequent reports of wolf depredation" as the reference for village

137 category, "Tibetan" as the reference for ethnicity, and "illiterate" as the reference for education level.

138 We used the Akaike information criterion corrected for small sample size (AICc) to compare

139 statistical models constituting different combinations of variables. We calculated $\triangle \mathrm{AICc}$, which means

140 the difference between the model with the lowest AICc and the other models in the model set. The

141 model with the lowest AICc was considered as the best model, when $\triangle \mathrm{AICc}$ between it and the next

142 best model was larger than two (Burnham \& Anderson 2002). However, if there were some models

143 whose $\triangle \mathrm{AICc}$ was $\leq 2$ (which means that these models had equivalent support to explain the data), we

144 used a normal model averaging approach over all candidate models to get parameters and error

145 estimates (Burnham \& Anderson 2002; Anderson 2008). We calculated the 95\% confidence interval

$146(95 \% \mathrm{CI})$ of parameter estimate and the odds ratio (OR) of the effects for each variable. We also

147 estimated the relative importance $\left(\mathrm{w}_{+}\right)$of a given variable by summing the Akaike weights of all

148 models containing the variable, and compared variables by examining the ratio of $\mathrm{w}_{+}$. Variables were

149 considered as associated statistically with the response variable, when their $95 \%$ CIs excluded the zone

150 value (Grueber et al. 2011). All analyses were performed on R 3.0.0 (R Development Core Team,

$1512013)$.

152

153 Results

154 In total, we interviewed 100 residents, of which 81 belonged to villages that reported wolf depredation

155 more frequently, and 19 to villages with less frequent reports of depredation. The respondents'

156 personal characteristics did not differ significantly between the two village categories (Table 1). 
157 Overall, they averaged 44 years of age, with $36 \%$ illiterate, $44 \%$ with elementary education, and $20 \%$

158 with secondary or higher education. Half of the respondents were Tibetan, and the other half were Han.

159 During the preceding three years, most families of the respondents owned livestock that they

160 grazed on alpine pastures. Most of them reported that their livestock suffered from depredation by

161 wolves (Table 2). The two village categories we defined did not differ significantly in livestock

162 ownership and percent of families experiencing depredation; however, there was a trend toward higher

163 mean annual livestock loss rate in villages that reported depredation more frequently compared with

164 those with less frequent reports of depredation (Table 2).

Most respondents in the more frequently depredated villages perceived an increase in wolf

166 populations, whereas more than half of respondents in the less frequently depredated villages perceived

167 a decrease in wolf populations in their areas (Table 3). With respect to people' attitudes towards

168 wolves, there was no significant difference between the two village categories (Table 3 ). The majority

169 of the respondents were negative in their attitude to wolves. All the people who were negative towards

170 wolves mentioned that livestock loss caused by wolves was the main reason for their attitude.

171 Therefore, they wanted to kill wolves and did not wish to protect them. Only very few $(3.6 \%, 3 / 84)$

172 people talked about fear of wolves, and no one mentioned an event of wolves attacking humans.

173 We constructed 64 candidate logistic regression models with six variables, where we excluded

174 one sample with mixed opinion towards wolves and two samples with missing values, to predict

175 variation of people' attitudes towards wolves. As there were 13 models with $\Delta \mathrm{AICcs} \leq 2$, we used a

176 model averaging approach to calculate estimates for variables. The results showed that the number of

177 livestock owned was the most important predictor, with the other five variables having lower relative

178 importance to it (Table 4). Only the number of livestock owned was statistically related to attitudes of

179 the respondents towards wolves, as its $95 \% \mathrm{CI}$ of the parameter estimate excluded the zero value.

180 People with a more negative attitude towards wolves owned larger numbers of livestock, on average 
181 (Fig. 2). For each additional animal owned, people were, on average, 1.032 times more likely to have a

182

183 184 185

186

187

188 189

190

191

192

193

194

195

196

197

198

199

200

201

202

203

204 negative attitude towards wolves (Table 4). Variation of attitudes towards wolves was not predicted by village category, the percentage of livestock depredated by wolves and factors associated with personal characteristics (i.e. ethnicity, age, and education level).

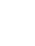

Discussion

Understanding the perceptions of local people living adjacent to wildlife habitats of wildlife-human interactions is important in the conservation of large carnivores, because they are apt to provide reliable information about wildlife (Treves \& Karanth 2003; White et al. 2005). However, it is difficult for the public to estimate wolf population sizes (Bjerke, Reitan \& Kellert 1998). In this study, we instead asked local people's opinions about wolf population trends. Similar studies have been previously conducted on other large carnivores, for example the Asiatic black bear Ursus thibetanus (Liu et al. 2011).

Most of the people we interviewed reported an increase in wolf populations in their areas in the preceding 10 years. The apparent increase in abundance may reflect effective protection and population recovery of the wolf in the wild since the prohibition of guns in 1996. This may have resulted in the increased livestock depredation and human-wolf conflicts as reported. Increase in human-wolf conflict may also be a result of human encroachment on wolves' natural habitats (Naughton-Treves, Grossberg \& Treves 2003) and ongoing degradation or loss of habitat (Yang 2008). In this case, wolves may more frequently encounter and prey on livestock as their natural prey populations have declined.

Nevertheless, more than half of respondents in the less frequently depredated villages perceived a decrease in wolf abundance in their areas. Insights that we have gained in these villages indicate that some people illegally killed wolves in their areas. It should be noted that livestock losses were selfreported in the interviews, and the reported magnitude of losses may differ from reality. It was hard to 
205 verify the magnitude of these reported losses in the present study, and thus we suggest that additional 206 research is needed on this topic.

207 As reported by some previous studies in other regions (e.g., Ericsson \& Heberlein 2003;

208 Naughton-Treves, Grossberg \& Treves 2003; Tuğ 2005; Røskaft et al. 2007), the local population had 209 a negative attitude to wolves. Attitudes toward wolves are strongly driven by physical and behavioral 210 characteristics of wolves as well as by some cultural and historical associations such as human fear of 211 wolves (Kleiven, Bjerke \& Kaltenborn 2004; Bisi et al. 2007; Suryawanshi et al. 2013). In our study, 212 the local people's explanation for negative attitude was livestock loss due to wolves, while very few 213 indicated fear of wolves. Despite widespread fear of wolves, attitudes may differ between areas and 214 groups as a result of different awareness of the biological characteristics of wolves, including 215 avoidance of humans (Bisi et al. 2007; Yang 2008).

216 However, our finding, that variation of attitudes was not explained by personal characteristics, 217 is inconsistent with previous studies in which people's attitudes towards wolves differed significantly 218 according to their age, education level and income (e.g., Ericsson \& Heberlein 2003; Naughton-Treves, 219 Grossberg \& Treves 2003; Tuğ 2005; Røskaft et al. 2007). We found that Tibetan people were as 220 negative as Han people, and this was not expected, as Tibetan groups, being Buddhist, find it easier to 221 accept the protection of wildlife than Han people who have no dominant religion (Eckel 1998). A 222 similar result was also reported by Liu et al. (2011) in the study on human-bear conflicts of western 223 Sichuan. It is possible that increase in conflicts between wolves and the local villagers at our study area 224 might have resulted in negative public opinion. We suspect, though, that Tibetan people would be less 225 likely to attack wolves in response to livestock loss or to engage in poaching, because of their belief 226 that killing wildlife could negatively affect their resurrection in the afterlife (Eckel 1998; Liu et al. 227 2011). 
Little research has examined the potential links between attitude and variables concerning

229 livestock. This study revealed that people with relatively large numbers of livestock were more likely

230 to have a negative attitude towards wolves than those with smaller numbers of livestock. To our

231 knowledge, there is no previous literature that has reported this phenomenon. In addition, we did not

232 find that people who had lost a larger percentage of their livestock to wolf depredation showed a more

233 negative attitude to wolves, as concluded by some previous studies concerning the wolf conflicts

234 (Williams, Ericsson \& Heberlein 2002; Ericsson \& Heberlein 2003; Naughton-Treves, Grossberg \&

235 Treves 2003; Tuğ 2005). We acknowledge that assigning zero predation to informants who had no

236 livestock would artificially reduce the predation intensity, thus may have affected the relationship

237 between livestock losses and attitude towards wolves. Unfortunately, because of small samples, we

238 cannot further test the effect of percent loss using only those informants who had livestock.

As an explanation, we suggest that the current finding might be associated with the fact that the

240 local people were impoverished and had seldom been compensated for their losses, while livestock

241 mortality by wolves was a relatively common occurrence. It is expected that people who grazed a

242 larger number of livestock and whose main source of income was from livestock, would be negative

243 towards anything that may cause loss of their livestock and threaten their income. Even if wolves had

244 not killed their livestock in the past, they would still have a negative attitude to wolves as they felt that

245 no one could guarantee the safety of their livestock in the future. In contrast, people with a smaller

246 number of livestock would expected to be neutral or positive in their attitude to wolves, as usually they

247 were able to obtain income from other sources and the economic benefits from livestock accounted

248 only for a small part of their incomes.

249

250 Management implications 
To mitigate future human-wolf conflicts, we must reduce livestock losses of local people who

252

253

254

255

256

257

258

259

260

261

262

263

264

265

266

267

268

269

270

271

272

273

274

suffer from wolf depredation. In our study site and related areas, a large livestock group is herded

commonly by a couple of people. Younger people are not willing to take up this lifestyle. Furthermore, existing corrals are poorly built. Ineffective guarding of livestock might have facilitated depredation by wolves (Jackson 2000; Treves \& Karanth 2003; Li et al. 2013). Therefore, we suggest that the best approach at present should be to improve guarding of livestock in the context of local cultures and conditions, for example, increasing the number of herders, developing expertise in herding, and building wolf-proof corrals using local materials (see Namgail, Fox \& Bhatnagar 2007).

Eco-compensation in mitigating human-wildlife conflicts has been increasingly emphasized by the government in recent several years (Xinhuanet 2014; Yunnan.cn 2014). Public education on wolf conservation has been conducted in our study area, but there has been no any provision of monetary compensation for herders who lost livestock to wolves. The local forestry department mentioned many obstacles, such as the difficulty of verifying the magnitude of livestock losses reported by local villagers. As an alternative approach, we could invest these monies in human resources and infrastructure, such as training herders and improving corrals. This will distribute the benefit equitably (Namgail, Fox \& Bhatnagar 2007). Furthermore, initiation of a livestock insurance program guided by the government, a measure that has proved effective in the India's Trans-Himalayan region (Mishra et al. 2003), is encouraged for a long-term management.

There are other alternatives such as relocation or limited removal of problem wolves (e.g., Mech \& Boitani 2003; Treves \& Karanth 2003; Bradley et al. 2005), and change of local livelihood (e.g., Jackson 2000; Conforti \& de Azevedo 2003; Li et al. 2013). The local government is considering employing armed police to kill problem wolves. Although a reported increase in the wolf populations and in livestock depredation by wolves in our study area, causal relationships between them are not clear. In addition, there is no scientific information on wolf population sizes. Therefore, this measure 
275 will require further data on wolf population sizes and their relations with livestock depredation. The

276 local government is also assisting herders to attempt to increase incomes from alternative sources, for

277 example eco-tourism and the cultivation of economically important alpine plants, aiming to reduce

278 their dependency on livestock. Two of the 12 villages we interviewed seemed to have been moving

279 toward a more positive attitude towards wolves. However, it should be noted that local people might

280 resist directions from authorities. Shift to other areas may also have different environmental impacts.

281 The forms of income generation should be implemented and sustained selectively through existing

282 institutions (Jackson 2000).

284 Conclusions

285 To conclude, this study investigated local villagers' perceptions of wolves in Jiuzhaigou County, 286 western China. Most people, especially in villages with more frequent reports of wolf depredation to 287 the local government, reported an increase of wolf population and thus increased livestock losses to 288 wolves. People were generally negative towards wolves, despite a prevalent Tibetan culture that favors

289 the protection of wildlife. These with a larger number of livestock were more likely to have a negative 290 attitude towards wolves. In term of conservation management, we suggest that improved guarding of

291 livestock and provision of monetary support on human resources and infrastructure may mitigate 292 human-wolf conflicts in this region. Our study provides insights into management of human-wolf 293 conflicts in western China.

295 Acknowledgements

296 We would like to thank Jiuzhaigou Forestry Bureau for help and support on this research. We thank 297 Xiaodong Gu (Sichuan Wildlife Resource Survey \& Conservation Management Station) for helpful 298 discussion on designing this survey, and Shulian Yang (Baihe Provincial Natural Reserve), Li Deng 
299 (Jiuzhaigou National Natural Reserve) and Yanmei Li (Gonggangling Provincial Natural Reserve) for

300 assistance with collecting data. Thanks also to Man Zhang (Sichuan University) and Hanqiu Yue

301 (Pingdingshan University) for their work on GIS-based mapping, and Pingjia Que (Beijing Normal

302 University) for guideline with statistical analysis. Thanks especially to Donald L. Kramer and three

303 anonymous reviewers who provided constructive suggestions to improve the manuscript.

304

305 References

306 Anderson DR. 2008. Model based inference in the life sciences: a primer on evidence. New York, NY:

$307 \quad$ Springer.

308 BBC News. 2006. China to promote wild animal hunt. Available at http://news.bbc.co.uk/2/hi/asia$309 \quad$ pacific/4775335.stm (accessed 23, February 2015).

310 Bisi J, Kurki S, Svensberg M, and Liukkonen T. 2007. Human dimensions of wolf (Canis lupus)

311 conflicts in Finland. European Journal of Wildlife Research 53:304-314.

312 Bjerke T, Reitan O, and Kellert SR. 1998. Attitudes toward wolves in southeastern Norway. Society and Natural Resources 11:169-178.

314 Bradley EH, Pletscher DH, Bangs EE, Kunkel KE, Smith DW, Mack CM, Meier TJ, Fontaine JA, Niemeyer CC, and Jimenez MD. 2005. Evaluating wolf translocation as a nonlethal method to

318 Burnham KP, and Anderson DR. 2002. Model selection and multimodel inference: a practical reduce livestock conflicts in the northwestern United States. Conservation Biology 19:1498information-theoretic approach. New York, NY: Springer-Verlag.

Chen LB. 2011. Overview of Jiuzgaigou County. Available at http://www.jzg.gov.cn/meilijzg/jzggk/jibxq/201103/t20110308_386680.html (accessed 15 March 2013). 
323

324

325

326

327

328

329

330

331

332

333

334

335

336

337

338

339

340

341

342

343

344

CNC. 2012. Wolf Attacks in N China. Available at http://www.cncworld.tv/news/v_show/30143_Wolf_Attacks_in_N_China_.shtml (accessed 20 March 2013).

Conforti VA, and de Azevedo FCC. 2003. Local perceptions of jagurs (Panthera onca) and pumas (Puma concolor) in the Iguacu National Park area, south Brazil. Biological Conservation 111:215-221.

Eckel MD. 1998. Is there a Buddhist philosophy of nature? In: Cohen RS, and Tauber AI, eds. Philosophies of Nature: The Human Dimension, vol.195. Dordrecht, The Netherlands: Kluwer Academic Publishers, 53-70.

Ericsson G, and Heberlein TA. 2003. Attitudes of hunters, locals, and the general public in Sweden now that the wolves are back. Biological Conservation 111:149-159.

Gros PM. 1998. Status of the cheetah Acinonyx jubatus in Kenya: a field-interview assessment. Biological Conservation 85:137-149.

Grueber CE, Nakagawa S, Laws RJ, and Jamieson IG. 2011. Multimodel inference in ecology and evolution: challenges and solutions. Journal of Evolutionary Biology 24:699-711.

Jackson R. 2000. Managing people-wildlife conflict on alpine pastures in the Himalayas. In: Richard C, Basnet K, Shah JP, and Raut Y, eds. Grassland Ecology and Management in Protected Areas of Nepal, Volume 3: Technical and Status Papers on Grasslands of Mountain Protected Areas. Kathmandu: ICIMOD (International Centre for Integrated Mountain Development), 98-118.

Kleiven J, Bjerke T, and Kaltenborn BP. 2004. Factors influencing the social acceptability of large carnivore behaviours. Biodiversity and Conservation 13:1647-1658.

4 Kvale S. 1996. Interviews: an introduction to qualitative research interviewing. London: Sage. 
345 Lescureux N, and Linnell JDC. 2013. The effect of rapid social changes during post-communist transition on perceptions of the human-wolf relationships in Macedonia and Kyrgyzstan. Pastoralism 3:1-20.

Li XY, Buzzard P, Chen YC, and Jiang XL. 2013. Patterns of livestock predation by carnivores: Human-wildlife conflict in northwest Yunnan, China. Environmental Management 52:13341340.

Liu F, McShea WJ, Garshelis DL, Zhu XJ, Wang DJ, and Shao LK. 2011. Human-wildlife conflicts influence attitudes but not necessarily behaviors: Factors driving the poaching of bears in China. Biological Conservation 144:538-547.

Mech LD, and Boitani L. 2003. Wolves: Behavior, Ecology, and Conservation. Chicago, IL: University of Chicago Press.

Mishra C, Allen P, McCarthy T, Madhusudan MD, Bayarjargal A, and Prins HHT. 2003. The role of incentive programs in conserving the snow leopard. Conservation Biology 17:1512-1520.

Namgail T, Fox JL, and Bhatnagar YV. 2007. Carnivore-caused livestock mortality in Trans-Himalaya. Environmental Management 39:490-496.

Naughton-Treves L, Grossberg R, and Treves A. 2003. Paying for tolerance: Rural citizens' attitudes toward wolf depredation and compensation. Conservation Biology 17:1500-1511.

White PCL, Jennings NV, Renwick AR, and Barker NH. 2005. Review: questionnaires in ecology: a review of past use and recommendations for best practice. Journal of Applied Ecology 42:421430.

R Development Core Team. 2013. R: a language and environment for statistical computing. Vienna, Austria: R Foundation for Statistical Computing.

Røskaft E, Händel B, Bjerke T, and Kaltenborn BP. 2007. Human attitudes towards large carnivores in Norway. Wildlife Biology 13:172-185. 
369 ScienceNet.cn. 2013. Wolves attacked frequently livestock on pastures. Available at http://news.sciencenet.cn/htmlnews/2013/6/278621.shtm (accessed 23, February 2015).

371 SCUSLS (Sichuan University School of Life Sciences). 2011. Comprehensive scientific survey report of Gonggangling Nature Reserve. Chengdu, China.

373 Skogen K, and Thrane C. 2007. Wolves in context: Using survey data to situate attitudes within a wider cultural framework. Society and Natural Resources 21:17-33. report of Jiuzhaigou Nature Reserve. Cheng, China.

Suryawanshi KR, Bhatnagar YV, Redpath S, and Mishra C. 2013. People, predators and perceptions: patterns of livestock depredation by snow leopards and wolves. Journal of Applied Ecology 50:550-560.

Treves A, and Karanth K. 2003. Human-carnivore conflict and perspectives on carnivore management worldwide. Conservation Biology 17:1491-1499.

Tuğ S. 2005. Conflicts between humans and wolf: A study in Bozdağ, Konya Province, Turkey. M. Sc thesis. Middle East Technical University.

Wang S. 1998. China red data book of endangered animals: Mammalia. Beijing: Science Press.

Wengraf T. 2001. Qualitative research interviewing: biographic narrative and semi-structured methods. London: Sage.

Williams CK, Ericsson G, and Heberlein TA. 2002. A quantitative summary of attitudes toward wolves and their reintroduction (1972-2000). Wildlife Society Bulletin 30:575-584.

Xinhuanet. 2014. Tibet spent over $\$ 14.5$ billion RMB on eco-compensation during the past 10 years. Available at http://news.xinhuanet.com/local/2014-05/03/c_1110508831.htm (accessed 26, February 2015). 
392 Yang HJ. 2008. Home range and habitat selection of wolf in the eastern grassland of the Inner Mongolia. Ph.D. thesis. Northeast Forestry University.

394 Yunnan.cn. 2014. Yunnan province has been innovating eco-compensation measures and insurance 395 indemnity for wildlife damage will be extended to the whole province. Available at 396 http://yn.yunnan.cn/html/2014-04/13/content_3171049.htm. (accessed 26, February 2015).

397 Zhang HH, Zou YA, Dou HS, Liu XP, Zhang CD, and Liu ST. 2010. Preliminary analysis on the 398 habitat selection of wolf (Canis lupus) in Dalai Lake Natural Reserve in Inner Mongolia. Acta Ecologica Sinica 30:3637-3644. 
Table $\mathbf{1}$ (on next page)

Comparison of respondents' personal characteristics between villages with more frequent reports of wolf depredation and those with less frequent reports of wolf depredation 


\begin{tabular}{|c|c|c|c|c|c|c|}
\hline \multirow[b]{2}{*}{ Village category } & \multirow{2}{*}{$\begin{array}{c}\text { Mean age } \\
\text { (range) }\end{array}$} & \multicolumn{2}{|c|}{ Proportion of ethnic groups } & \multicolumn{3}{|c|}{ Proportion of education levels } \\
\hline & & Tibetan & Han & Illiterate & $\begin{array}{c}\text { Elementary } \\
\text { school }\end{array}$ & $\begin{array}{l}\text { Secondary } \\
\text { and above }\end{array}$ \\
\hline $\begin{array}{l}\text { Villages with more frequent } \\
\text { reports of depredation }(\mathrm{n}=9 \\
\text { villages, and } 81 \text { respondents) }\end{array}$ & $\begin{array}{c}44 \\
(16-81)\end{array}$ & $\begin{array}{l}49.4 \% \\
(40 / 81)\end{array}$ & $\begin{array}{l}50.6 \% \\
(41 / 81)\end{array}$ & $\begin{array}{l}34.6 \% \\
(28 / 81)\end{array}$ & $\begin{array}{l}45.7 \% \\
(37 / 81)\end{array}$ & $\begin{array}{l}19.8 \% \\
(16 / 81)\end{array}$ \\
\hline $\begin{array}{l}\text { Villages with less frequent } \\
\text { reports of depredation }(n=3 \\
\text { villages, and } 19 \text { respondents) }\end{array}$ & $\begin{array}{c}46 \\
(23-77)\end{array}$ & $\begin{array}{l}52.6 \% \\
(10 / 19)\end{array}$ & $\begin{array}{l}47.4 \% \\
(9 / 19)\end{array}$ & $\begin{array}{l}42.1 \% \\
(8 / 19)\end{array}$ & $\begin{array}{l}36.8 \% \\
(7 / 19)\end{array}$ & $\begin{array}{l}21.1 \% \\
(4 / 19)\end{array}$ \\
\hline Statistical tests & $\begin{array}{c}\mathrm{t}=-0.536, \mathrm{df}= \\
98, \mathrm{P}=0.593\end{array}$ & $\chi^{2}=0.065$ & $\mathrm{P}=0.799$ & $\chi^{2}=0$ & $29, \mathrm{df}=2, \mathrm{P}$ & $=0.768$ \\
\hline
\end{tabular}


Table 2 (on next page)

Comparison of estimates of livestock ownership and livestock depredation between villages with more frequent reports of wolf depredation and those with less frequent reports of wolf depredation 


\begin{tabular}{|c|c|c|c|c|}
\hline Village category & $\begin{array}{c}\text { Percentage of } \\
\text { families with } \\
\text { livestock grazed }\end{array}$ & $\begin{array}{l}\text { Average annual number } \\
\text { of livestock owned per } \\
\text { family (range) }\end{array}$ & $\begin{array}{c}\text { Percentage of families } \\
\text { with livestock } \\
\text { depredated by wolves }\end{array}$ & $\begin{array}{l}\text { The reported annual } \\
\text { livestock loss rate to } \\
\text { wolves (range) }\end{array}$ \\
\hline $\begin{array}{l}\text { Villages with more frequent } \\
\text { reports of depredation }(n=9 \\
\left.\text { villages, and } 81 \text { respondents }{ }^{a}\right)\end{array}$ & $86.3 \%(69 / 80)$ & $41(4-200)$ & $82.6 \%(57 / 68)$ & $21.7 \%(0-70 \%)$ \\
\hline $\begin{array}{l}\text { Villages with less frequent } \\
\text { reports of depredation ( } \mathrm{n}=3 \\
\text { villages, and } 19 \text { respondents) }\end{array}$ & $73.6 \%(14 / 19)$ & $53(3-200)$ & $64.3 \%(9 / 14)$ & $11.7 \%(0-30 \%)$ \\
\hline Statistical tests & $\begin{array}{c}\text { Fisher's exact test } \mathrm{P} \\
=0.184\end{array}$ & $\begin{array}{c}\mathrm{t}=-0.981, \mathrm{df}=81, \mathrm{P}= \\
0.330\end{array}$ & $\begin{array}{c}\text { Fisher's exact test } \mathrm{P}= \\
0.134\end{array}$ & $\begin{array}{c}\mathrm{t}=1.180, \mathrm{df}=80, \mathrm{P}= \\
0.074\end{array}$ \\
\hline
\end{tabular}

$2{ }^{a}$ no data values were recorded for livestock ownership and livestock depredation in one sample, and there is one missing value for livestock 3 depredation in another sample. 
Table 3(on next page)

Comparison of respondents' opinions about wolf population trends and attitudes towards wolves between villages with more frequent reports of wolf depredation and those with less frequent reports of wolf depredation 


\begin{tabular}{|c|c|c|c|c|c|c|c|}
\hline \multirow[t]{2}{*}{ Village category } & \multicolumn{3}{|c|}{$\begin{array}{c}\text { Proportion of opinions about wolf } \\
\text { population trends }\end{array}$} & \multicolumn{4}{|c|}{ Proportion of attitudes towards wolves } \\
\hline & Increasing & Decreasing & Stable & Negative & Positive & Neutral & Mixec \\
\hline $\begin{array}{l}\text { Villages with more frequent reports of } \\
\text { depredation ( } n=9 \text { villages, and } 81 \\
\text { respondents) }\end{array}$ & $\begin{array}{l}79.0 \% \\
(64 / 81)\end{array}$ & $\begin{array}{l}16.0 \% \\
(13 / 81)\end{array}$ & $\begin{array}{l}4.9 \% \\
(4 / 81)\end{array}$ & $\begin{array}{l}86.4 \% \\
(70 / 81)\end{array}$ & $\begin{array}{l}7.4 \% \\
(6 / 81)\end{array}$ & $\begin{array}{l}4.9 \% \\
(4 / 81)\end{array}$ & $\begin{array}{l}1.2 \% \\
(1 / 81)\end{array}$ \\
\hline $\begin{array}{l}\text { Villages with less frequent reports of } \\
\text { depredation ( } n=3 \text { villages, and } 19 \\
\text { respondents) }\end{array}$ & $\begin{array}{l}47.4 \% \\
(9 / 19)\end{array}$ & $\begin{array}{l}52.6 \% \\
(10 / 19)\end{array}$ & $\begin{array}{c}0 \\
(0 / 19)\end{array}$ & $\begin{array}{l}73.7 \% \\
(14 / 19)\end{array}$ & $\begin{array}{l}26.3 \% \\
(5 / 19)\end{array}$ & $\begin{array}{c}0 \\
(0 / 19)\end{array}$ & $\begin{array}{c}0 \\
(0 / 19)\end{array}$ \\
\hline Statistical tests & Fisher's & xact test $P=$ & 0.005 & Fish & r's exact te & $\overline{\mathrm{tP}}=0.11$ & \\
\hline
\end{tabular}


Table 4(on next page)

Model-averaged coefficients and relative importance calculated for variables explaining variation in attitude of respondents towards wolves 


\begin{tabular}{|c|c|c|c|c|c|c|c|}
\hline Variable & Estimate & $\mathrm{SE}$ & Lower $95 \% \mathrm{CI}$ & Upper 95\% CI & OR & $\mathrm{z}$ value & $\mathrm{Wi}_{+}$ \\
\hline Intercept & 0.175 & 1.115 & -2.010 & 2.360 & 1.191 & 0.156 & \\
\hline ANL & 0.032 & 0.016 & 0.001 & 0.062 & 1.032 & 2.018 & 0.93 \\
\hline Ethnicity_Han ${ }^{\mathrm{a}}$ & 1.082 & 0.747 & -0.382 & 2.546 & 2.951 & 1.432 & 0.53 \\
\hline Village category_less frequent reports of wolf & -0.945 & 0.687 & -2.293 & 0.402 & 0.389 & 1.358 & 0.46 \\
\hline \multicolumn{8}{|l|}{ depredation $^{\mathrm{b}}$} \\
\hline APL & 2.144 & 1.806 & -1.395 & 5.683 & 8.534 & 1.173 & 0.44 \\
\hline Age & 0.025 & 0.024 & -0.022 & 0.072 & 1.025 & 1.038 & 0.38 \\
\hline Education level_secondary and above ${ }^{c}$ & 0.370 & 0.870 & -1.335 & 2.075 & 1.447 & 0.42 & 0.32 \\
\hline Education level_elementary school & 0.599 & 0.674 & -0.721 & 1.920 & 1.821 & 0.878 & - \\
\hline
\end{tabular}

2

a"Tibetan" was the reference category

$3 \mathrm{~b}$ "Villages with more frequent reports of wolf depredation" was the reference category

4 c"Illiterate" was the reference category

5 Abbreviations: ANL, annual number of livestock the respondent's family grazed; APL, annual percentage of livestock depredated by wolves; 6 OR, the odds ratio. 
1

Map showing the study area, Jiuzhaigou County, Sichuan Province, western China, as well as locations of villages investigated in the study

The dark circles represent villages with more frequent reports of wolf depredation, and the dark squares villages with less frequent reports of wolf depredation 

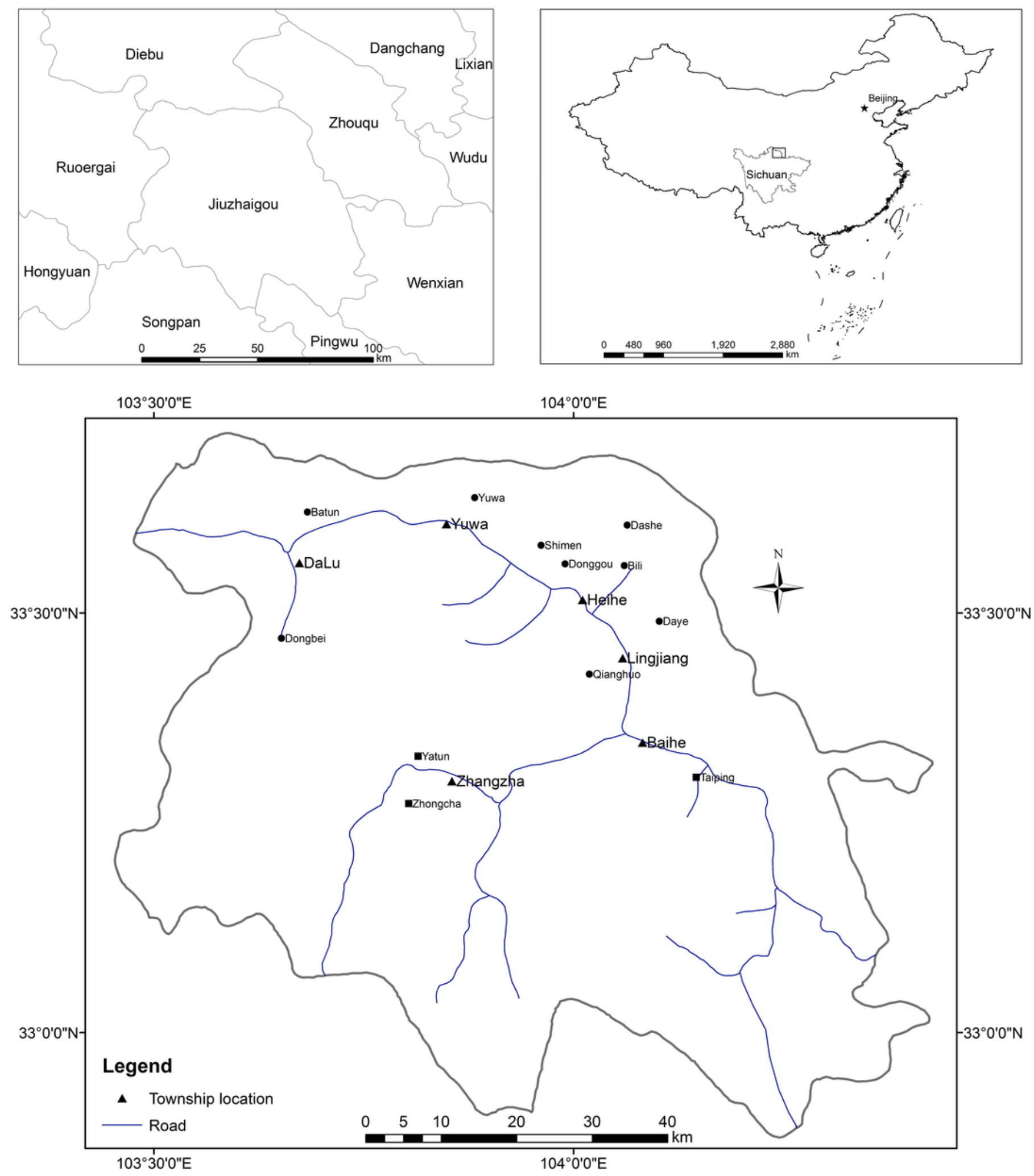
Figure 2 (on next page)

Mean annual number of livestock \pm 1 SE grazed by families of respondents who had different attitudes towards wolves 


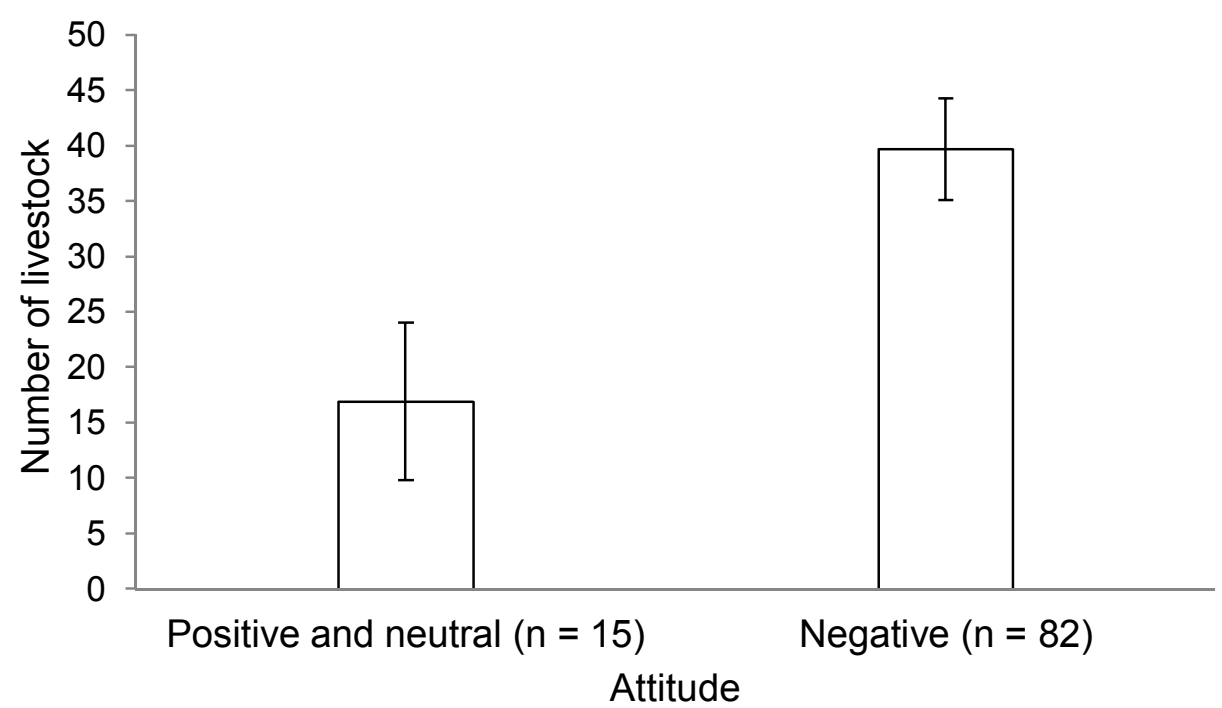

